\title{
INTERNATIONAL SUMMER SCHOOL SCHMALKALDEN: AN INTERNATIONAL ECONOMICS AND CROSS-CULTURAL MANAGEMENT PROGRAM
}

\author{
Willie J. Redmond, Southeast Missouri State University, Cape Girardeau, Missouri, USA \\ Robert Richert, FH Schmalkalden University of Applied Sciences, Schmalkalden, Germany \\ Peter Gordon, Southeast Missouri State University, Cape Girardeau, Missouri, USA \\ Francisco Barbosa, Universidade Federal de Minas Gerais, Belo Horizonte, Brazil
}

dx.doi.org/10.18374/JABE-13-3.9

\begin{abstract}
This paper first examines the role that cultural differences play in the increasingly globalized climate of the new millennium. Then, it discusses responses that education can give to ensure that upcoming generations are globally competent and thus aware of the challenges that are ahead. Finally one such effort, the International Summer School Schmalkalden (ISSS) is discussed. The primary goal of the ISSS is that participating students will be offered (and be able to develop through the exchange of perspectives and experiences) detailed knowledge and understanding of the complex and interwoven challenges facing economies and firms in this twenty-first century. The belief is that by creating a better understanding of cross-cultural attitudes, it can lead to more acceptance and cooperation among relevant economic and cultural players.
\end{abstract}

Keywords: International Business, Culture, Education 